\title{
An Analysis of Expressive Utterances Produced by The Characters in The Movie Entitled Spongebob Squarepants \\ (A Pragmatic Study)
}

\author{
Suko Raharjo \\ English Education Department \\ Teacher Training and Education Faculty \\ Sebelas Maret University of Surakarta
}

Email: suko_english@yahoo.co.id

\begin{abstract}
This article reports the result of research on expressive utterances produced by the characters in the movie entitled SpongeBob SquarePants. The objectives of the research are (1) to find out the characteristics of expressive utterances produced by the characters; and (2) to find out the variability of expressive utterances. This research uses descriptive qualitative method. The source of data is the transcript of SpongeBob SquarePants movie. The research findings show that (1) there are four sentence types of expressive utterances that are employed in SpongeBob SquarePants movie transcript, that is, ellipsis (19 utterances), declaratives (13 utterances), interogative (1 utterances), and imperatives (4 utterances); (2) there are six notions of expressive utterances found in the SpongeBob SquarePants movie transcript, that is, surprise (2 utterance), happiness (14 utterances), anger (6 utterances), apologize (5 utterances), congratulate (1 utterance), and thanks (7 utterances).
\end{abstract}

Keywords: analysis, expressive, qualitative, transcript.

\section{INTRODUCTION}

Naturally, people use language to communicate. They use language to tell others what they know or think they know, to express their feeling, ask question, make a request, comment, protest, criticize, insult, apologize, promise, thank, and greet (Kreidler, 1998: 176). Language is divided into written and oral form.Written language is just written on the paper, whereas oral language is spoken by speaker and oral language can be expressed directly to state the speaker"s feeling through the utterances which can be listened to by the people and finally, they understand the speaker"s meanings.

According to Kreidler (1998: 26), an utterance is an act of speech or writing; it is a specific event, at a particular time and place.It involves at least one person, the one who produces the utterance, but usually more than one person. It means that utterance is words that are produced by one or more speakers in both oral and written form. An utterance just occurs at one time because it is orally expressed through words by the speaker to state a particular purpose. A spoken utterance happens and then disappears, unless it is recorded electronically with recorded devices. In this case, the utterance can occur many times because it can be repeated by the recorded devices.

An utterance is spoken by the people. In English, there are many utterances uttered by the people in their daily life. These 
utterances as the oral language in English to state the speakeres meanings to the hearer. This statement related to the pragmatic study.Pragmatics is the study of speaker"s meaning (Yule, 1996: 3) . Pragmatics formed as utterances in English and is expressed orally from the speaker to hearer such as: state, order, ask, command, apologize, promise, refuse, declare, etc., for example:

Mother: "Can you help me to lift this box?". Son: "Yes, of course mom”.

This expression is a request from a mother to her son. The mother is the speaker and the son as the hearer. She utters Can you help me to lift this box? to express a request to him because she requires his help to lift a box and her son is able to help her by uttering Yes, of course mom.

In daily life, there are so many utterances uttered by people to express something. These utterances are integrated as one unit of speech acts in pragmatic study. Searle (1976: 10) states there are five kinds of speech acts: representative, directive, commisive, expressive, and declarative. These five kinds of speecch acts are employed in the people,s daily conversations, either formal or non-formal communications, not only among people, but also in a movie or a drama which forms dialogues between two or more people. The dialogues in both movie and drama contain words, sentences, and utterances forms literature in a language.

\section{RESEARCH METHODS}

This research belongs to descriptive qualitative research, it means that the data in this research are words and sentences belonging to expressive utterances in the movie "Sponge Bob Square Pants". The researcher attempts to collect, analyze, interprete, and make conclusion the data of movie "Sponge Bob Square Pants". Surakhmad (1994) says that descriptive method is carried out by collecting, arranging, analyzing, and interpreting the data. The intended data are sentences, pictures, and non-numericals. Whereas, qualitative research is a research focusing on non-numerical data which doesn ${ }^{e e}$ has statistic measurement. Dornyei (2007) also states that qualitative research involves data collecting procedure that result primarily in open-ended, non-numerical data are analyzed by non-statistic method. On the other hand, Sutopo (2002) argues that in qualitative research, the collected data are particularly in form of words, sentences, and pictures that have more meaning than number of quantity or frequency. Thus, in descriptive qualitative research, the obtained data are non-numericals data such as: words, sentences, and pictures then these data are collected, arranged, analyzed, interpreted, and made conclusion to be a result of the research.

This research belongs to descriptive qualitative research, it means that the data in this research are words and sentences belonging to expressive utterances in the movie "Sponge Bob Square Pants".The intended words and sentences are expressive utterances in the movie transcript which belongs to surprise, happiness, sorrow, blame, apologize, anger, congratulate, and thanks. After getting the movie transcript. the researcher tries to analyze every utterance produced by the characters in the movie then he interpretes which utterances are expressive. The last, he makes conclusion the data belonging to expressive uterances in the movie transcript. The data in this research are got prosedurally, from the researcher attempts to collect, analyze, 
interprete, and make conclusion the data in the movie transcript of "Sponge Bob Square Pants".

In this research, the researcher employs a purposive sampling technique. According to Sutopo (2002), in the purposive sampling, selection of the sample is directed to the data that have important relation with the problem being observed. Thus, purposive sampling employs selected data relating to the research as sample. On the other hand, in random sampling, data selected at random, so all the data are sample(Blaxter, Hughes, and Tight, 1996). Therefore, the researcher only uses the data related to the field of study. In this case, the related data are expressive utterances produced by the characters in the movie entitled SpongeBob SquarePants.

Based on some criteria of the data, the data used in this research are the selecteddata containing expressive expressions. Those criteria are based on the communicative functions showing the expressive types such as: surprise, happiness, sorrow, anger, blame, apologize, congratulate, and thank by considering the context of situation where the speech acts are uttered.

The tecnique of collecting data is meant to set up the direction in conducting the research. Surakhmad (1994) states that in obtaining the maximum result, a researcher tries to explain each step of the descriptive research in accuracy and detail. The Step of collecting data in this research are as follows: (1) watching the movie "Sponge Bob Square Pants" for several times in order to understand the story, (2) searching for the script in the internet, (3) underlining the dialogues in the transcript containing expressive speech acts, (4) taking note on all the words and sentences containing expressive speech acts as the data of the research, (5) identifying each datum based on the types of expressive speech acts, and (6) giving codes on each datum.

Blaxter, Hughes, and Tight (1996) defines coding as the process by which items or groups of data are assigned codes. These may be used to simplify and standardize the data for analytical purposes. It ${ }^{\text {ee }} \mathrm{s}$ intended to distinguish the data which will be analyzed based on related study. The researcher makes the codes by using abbreviations to assign the data of expressive speech acts in the movie entitled "SpongeBob SquarePants". The coding of the data in this research is as follows: (1) the number for each datum, (2) the title of the movie "SpongeBob Square Pants" is abbreviated SBSP, and (3) the type of expressive speech acts employed by the characters covers: surprise is abbreviated into Sur, happiness is abbreviated into Hap, sorrow is abbreviated into Sor, anger is abbreviated into Ang, blame is abbreviated into Bla, apologize is abbreviated into Apo, congratulate is abbreviated into Cong, and thank is abbreviated into Tha

To make clearer of the coding, an example will be presented:

\section{(01 / SBSP / Sur)}

It means the datum is number 01 . SBSP is the abbreviation of the title of the movie "Sponge Bob Square Pants". Sur means that the character employs a surprise expression.

Analyzing is one of steps in descriptive research which is intended to find out the research data. It is the important step in doing descriptive research because of from this step the result of research is obtained. Blaxter, Hughes, and Tight argues that analyzing is an ongoing process which 
may occur throughout the research, with earlier analysis informing later data collection.

After doing the steps of collecting the data, the researcher analyzes them by doing some activities as follows: (1) describing the context of the situation where the dialogue takes place, (2) identifyng the characteristics of expressives based on the Searle ${ }^{\text {ee }}$ s theory, and (3) finding out the variability of expressive speech acts.

\section{RESEARCH DISCUSSION}

FINDING

AND

Data analysis explains how the researcher analyzes the expressive utterances in the transcript of SpongeBob SquarePants movie. He analyzes them based on Searle ${ }^{\text {ee }} \mathrm{s}$ theory that categorizes expressives into eight: surprise, happiness, sorrow, anger, blame, apologize, congratulate, and thanks. Before analyzing the expressive utterances in the movie entitled SpongeBob SquarePants, the researcher takes the steps to analyze the expressive utterances as follows: (1) choosing sample of utterance: the researcher identifies the expressive utterances in the movie and those are identified based on the Searle ${ }^{\text {ee }}$ theory. They are taken from the transcript of SpongeBob SquarePants movie, (2) identifying Context: the researcher identifies the context and the condition of characters of the movie, then (3)doing analysis: the researcher identifies three aspects of speech acts in expressive utterances to be analyzed, including the locution, illocution, and perlocution. In this case, the researcher considersthe intended mean of the expressive utterances.

\section{A. Surprise}

1. Sample of utterance: (02/SBSP/Sur)

a. Mindy: Good. Now, keep your eyes shut. [Grabs two sea weed and puts them onto SpongeBob and Patrick as mustache] With my mermaid's magic and my one tailfin [Patrick giggles], I command the two of you to turn into men! Open your eyes.

b. SpongeBob: I don't feel any... [Notices that Patrick has a "mustache"] Oh, mv gosh. Patrick. you have a mustache!

c. Patrick: So do you!

d. Mindy: So now that you're men, can you make it to Shell City? [SpongeBob and Patrick adores their mustaches] Guys!

\section{Context:}

The dialogue above takes place in canyon. The characters are Mindy, SpongeBob and Patrick. Mindy wants both SpongeBob and Patrick to turn into men. Therefore, she has them to close their eyes by putting two sea weeds onto SpongeBob and Patrick as mustache. While opening his eyes, SpongeBob gets surprised by saying "Oh my gosh, Patrick, you have a mustache!" because he sees Patrick has mustache. Mindy declares SpongeBob and Patrick as men because they have mustaches.

\section{Analysis:}

a. Locution: a declarative sentence.

b. Illocution: SpongeBob expresses his surprise that Patrick gets a mustache.

c. Perlocution: Patrick gets surprised too and he touch his mustache. 


\section{B. Happiness}

1. Sample of utterance:

(07/SBSP/Hap)

a. Patrick: By car.

b. SpongeBob: I wish we still had our car.

\section{c. Patrick:SpongeBob, look!}

d. SpongeBob and Patrick: Our car! [We see the Patty Wagon in front of a beat-up bar. SpongeBob and Patrick are about ready to get in the Patty Wagon, but SpongeBob notices that the key is missing]

e. SpongeBob: The key!

2. Context:

The dialogue above takes place in middle of desert and the characters are SpongeBob and Patrick. Patrick and SpongBob walk away together in the middle of desert. They look so thirsty and tired. They want to go to Shell City. After SpongeBob sees a sign that shows time to get Shell City along 2 days by car. SpongeBob wish they still had car. Suddently, Patrick find a car and he is happy by saying "SpongeBob, look!" because they get a car to get Shell City.

\section{Analysis:}

a. Locution: imperative.

b. Illocution: Patrick has SpongBob have a look something, that is a car.

c. Perlocution: hearing the expression, the hearer will do what the speaker says.

\section{Anger}

1.Sample of utterance: (05/SBSP/Ang) a. SpongeBob and Patrick: Hooray! Bubble party! [The duo parties with the bubbles. One floats out of the restroom and into the Thug Tug bar]

b. Thug Tug Owner:Hev! Who blew this bubble? You all know the rules!

c. Everybody in the Thug Tug: All bubble-blowing babies will be beaten senseless by every able-bodied patron in the bar.

d. Thug Tug Owner: That's right! So who blew it? So nobody knows.

e. [SpongeBob and Patrick burst bubbles]

2. Context:

The dialogue above takes place at the Thug Tug bar and the characters are SpongeBob, Patrick, Thug Tug Owner, and Everybody in the Thug Tug. SpongeBob and Patrick are having Bubble party at the bathroom. One bubble floats out of the restroom and into the Thug Tug bar. It causes Thug Tug Owner be angry by saying "Hey! Who blew this bubble?" to everybody in the Thug Tug. He feels the bubble disturb his bar.

3. Analysis:

a. Locution: an interogative sentence.

b. Illocution: Thug Tug Owner asks everybody in the Thug Tug who blew that bubble angryly .

c. Perlocution: hearing the expression, the hearer will answer the speaker"s question.

\section{Apologize}

1. Sample of utterance: (01/SBSP/Apo)

a. SpongeBob: Eww, I think I stepped in something.

b. [Tries to scrape Plankton off] 
c. Plankton: Not in something, on someone, you twit!

d. SpongeBob:Oh. Sorry, Plankton.[Pulls him off his shoe] Are you on your way to the grandopening ceremony?

e. Plankton: No, I am not on my way over to the grand-opening ceremony. I'm busy planning to rule the world!

2. Context:

The dialogue above takes place on the road and the characters are SpongeBob and Plankton. SpongeBob runs from the Squidward ${ }^{\text {ee }}$ s house to grand opening ceremony in the Krusty Krabs. When he runs in the middle of the way, he feels his foot step in something then he stops and look at the shoe. He finds Plankton under his shoe. Finally, he apologizes him by saying "Oh, Sorry, Plankton" because he steps in Plankton.

3. Analysis:

a. Locution: ellipsis.

b. Illocution: SpongeBob expresses an apology that he steps in Plankton.

c. Perlocution: hearing the expression, the hearer will reponse the speaker"s mean.

\section{E. Congratulation}

1. Sample of utterance: (01/SBSP/Cong)

a. Patrick: That sounds like the manager of the new Krusty Krab 2.[Realizes that he doesn't have his trunks on] Oops. Hold on.[Rock closes, with Patrick on it. Then it opens again]Congratulations. buddy. b. SpongeBob: Oh, thanks, Patrick. And tonight, after my big promotion, we're gonna party till we're purple.

c. Patrick: GOD I LOVE BEING PURPLE!

d. SpongeBob: We're going to the place where all the action is.

\section{Context:}

The dialogue above takes place in front of Squipward ${ }^{\text {es }}$ house and the characters are SpongeBob and Patrick. Patrick thinks that SpongeBob has been elected as a new manager of Krusty Krabs 2. So, he congratulates SpongeBob by saying "Congratulation, buddy" because SpongeBob is the new manager of Krusty Krabs 2.

3. Analysis:

a. Locution: ellipsis.

b. Illocution: Patrick expresses a congratulation that SpongeBob is the new manager of Krusty Krabs 2.

c. Perlocution: hearing the expression, the hearer will thank to the speaker.

\section{F. Thank}

1. Sample of utterance: (01/SBSP/Tha)

a. Patrick: That sounds like the manager of the new Krusty Krab 2.[Realizes that he doesn't have his trunks on] Oops. Hold on.[Rock closes, with Patrick on it. Then it opens again] Congratulations, buddy.

b. SpongeBob:Oh, thanks,

Patrick.And tonight, after my big promotion, we're gonna party till we're purple. 


\section{c. Patrick: GOD I LOVE BEING PURPLE!}

d. SpongeBob: We're going to the place where all the action is.

2. Context:

The dialogue above takes place in front of Squipward ${ }^{\text {ee }}$ s house and the characters are SpongeBob and Patrick. Patrick congratulates SpongeBob because SpongeBob is the new manager of Krusty Krabs 2 . SpongeBob thanks to Patrick by saying "Oh, thanks, Patrick" because Patrick congratulates him for being the new manager of Krusty Krabs 2.

3. Analysis:

a. Locution: ellipsis.

b. Illocution: SpongeBob expresses a thank that Patrick congratulates him for being the new manager.

c. Perlocution: hearing the expression, the hearer will say something to the speaker.

\section{CONCLUSION, IMPLICATION, AND SUGGESTION}

Based on the data analysis above, the reseacher concludes that (1) There are four sentence types of expressive utterances that are employed in SpongeBob SquarePants movie transcript, that is, ellipsis, declaratives, interogative, and imperatives

(2) There are six notions of expressive utterance found in the SpongeBob SquarePants movie transcript, that is surprise, happiness, anger, apologize, congratulate, and thanks.

Expressive utterances as used in the SpongeBob SquarePants movie transcript can be employed in English learning activity in the class. Expressive utterance can be used for classroom interaction between teacher and the students, and student among the students based on its contexts. An expressive utterance in the form of ellipsis can be used by the teacher and the students, for example when a student can answer a question then the teacher says: "Right", "Good", "Welldone ", "That's right", and "Okay, that great"

Declarative sentence can be used both by the teacher and the students, for example when there is a student comes late, he or she says:"I am sorry Sir, I am late because I miss the bus" and "Sorry for coming late, I wake up late" . Declarative sentence can be used by a student who didn"t do the homework says: "I am sorry Sir, I didn"t do the homework" and "I apologize for not doing my homework". Declarative sentence can also be used by the teacher when one students is absent because he is sick, where he says: "Oh, I am sorry to hear that". Therefore, from the above explanation the researcher concludes that all the linguistic form of expressive utterances can be implemented in the classroom interaction based on its contexts.

In this research, the research uses expressing personal feeling to teach speaking in English by using a role play technique. Brown (1994: 268-240) in the principle of teaching speaking says that the teacher can use many kinds of attractive language teaching technique like jigsaw group technique, play a game or discussing solution to the environmental crises. Researcher thinks role play is an attractive language teaching technique to teach speaking to the students because role play motivates the students to practice speaking skill more in group through communicative activity. 
The researcher hopes that this research will give such a contribution or recomendation to learners and other researchers as follows: (1) English Department students who are interested in pragmatics study are expected to understand well the characteritics of expressive utterances as well as to implement the expressive utterances English classroom interaction, (2) High school students are expected to understand the expressive utterances in expressing personal feelings which is used in English lesson, and (3) as the researcher only explains the expressive utterances taken from SpongeBob SquarePants movie transcript, he does not cover all the classification of speech acts that exist. The researcher hopes that there will be researchers who are interested in conducting similar research on expressive utterances and classifying them based on speech acts by taking subjects other than SpongeBob SquarePants movie transcript.

\section{BIBLIOGRAPHY}

Blaxter, J., Hughes, C.,\& Tight, M. (1996). How To Research. Philadelphia: Open University Press.

Brown, H.D. (1994). Teaching By Principle: An Interactive Approach
To Language Pedadogy. New Jersey: Prentice Hall Regent

Dornyei, Z. (2007). Research Method in Applied Linguistics: Quantitative, Qualitative, and Mixed Methodologies. New York: Oxford University Press.

Kreidler, C.W. (1998). Introducing English Semantic. New York: The Taylor and The Francais.

Searle, J.R. (1976). Speech Acts An Essay in the Philosophy of Language. Cambridge: Cambridge University Press.

Searle, J.R. (1976). A Classification of Illocutionary Acts. Language in Society, Vol. 5, No. 1 (Apr., 1976), pp 1-23. Diperoleh 5 Oktober 2013, dari http://www.jstor.org/stable/4166848.

Surakhmad, W. (1994). Pengantar Penelitian Ilmiah: Dasar Metode Teknik. Bandung: Tarsito Bandung.

Sutopo, H.B. (2002). Metodologi Penelitian Kualitatif: Dasar Teori dan Terapannya dalam Penelitian. Surakarta: Sebelas Maret University Press.

Yule, G. (1996). Pragmatics. Oxford: Oxford University Press 